\title{
Ensinando professoras a analisar e interpretar dados como parte de uma análise de contingências
}

\author{
Carolina Porto de Almeida \\ Maria Eliza Mazzilli Pereira \\ Pontifícia Universidade Católica de São Paulo
}

\begin{abstract}
Resumo
O presente estudo teve por objetivo ensinar três professoras de Educação Infantil a realizar parte de uma análise de contingências: a análise e a interpretação de dados sobre o comportamento de um aluno. Foram exibidos 14 filmes, os quais mostravam uma professora aplicando um método de análise de contingências a comportamentos considerados inadequados de um aluno, sendo tais comportamentos mantidos pela atenção da professora ou pela fuga de tarefas escolares. As participantes observaram e registraram a ocorrência ou não ocorrência do comportamento-alvo, o evento antecedente e a consequência, em intervalos de 30 segundos. Posteriormente, responderam a questões de análise e interpretação de dados. O procedimento foi composto por: Pré-teste; Ensino e Pós-teste. No Pré-teste, erraram a maioria dos registros, assim como as respostas às questões. No Pós-teste, acertaram praticamente todos os registros e as respostas, sugerindo-se a efetividade das estratégias utilizadas para ensiná-las a analisar e interpretar dados em um período relativamente curto.

Palavras-chave: análise de contingências; análise e interpretação de dados; capacitação de professores.
\end{abstract}

\begin{abstract}
Teaching school-teachers to analyze and to interpret data as part of a contingency analysis.

The purpose of this study was to teach three school-teachers to perform part of a contingency analysis: the analysis and interpretation of data about a student's behavior. Fourteen movies were exhibited, which showed a teacher implementing a method of contingency analysis to a student's behaviors. These behaviors were maintained either by the teacher's attention or by escape from academic tasks. Participants observed and recorded the occurrence or non occurrence of the student's target behavior, the antecedent event and the consequence, at 30 second intervals. Afterwards, they answered questions on data analysis and interpretation. The procedure was composed by: Pre-test, Training Procedures and Post-test. On Pre-test, participants made mistakes in the majority of the records and answers to the questions. On Post-test, almost all the records and the answers were correct, which suggests the effectiveness of the training to teach them to analyze and interpret data in a relatively short time.
\end{abstract}

Key-words: contingency analysis; data analysis and interpretation; teacher's training.

$\mathrm{M}$ uitos estudos sobre análise funcional do comportamento são encontrados na literatura, e diversas são as linhas de pesquisa em que eles estão inseridos. De acordo com Matos (1999), a análise funcional pode ser entendida como a "explicação" dada a um evento por meio da descrição de sua relação com outros eventos, denominados antecedentes e consequentes. Ao apresentar essa definição, a autora ainda afirma que a análise funcional nada mais é do que uma análise das contingências relacionadas a um comportamento ou a mudanças nesse comportamento, seja ele problemático ou aceitável.

Entre as diferentes linhas de pesquisa com o objetivo de estudar procedimentos de análise funcional do comportamento, uma delas é decorrente de um método de aplicação de análise funcional, seguindo a proposta de Iwata, Dorsey, Slifer, Bauman e Richman (1994). Na proposta de Iwata et al. (1994), enfatiza-se, caracteristicamente, a possibilidade de se realizar uma análise funcional rápida, a fim de testar a função do comportamento de um indivíduo em poucas sessões, com uma duração total de poucas horas, antes de se escolher e aplicar uma intervenção mais longa.

São numerosas as citações sobre esse método, principalmente nas investigações que simulam situações análogas às naturais para identificar as variáveis que estariam controlando um comportamento visto como inadequado (Carr, Langdon, \& Yarbrough, 1999; Iwata et al., 2000; Myers \& Holland, 2000; Repp \& Horner, 1999; Roscoe, Carreau, MacDonald, \& Pence, 2008; Wallace, Doney, Mintz-Resudeck, \& Tarbox, 2004).

O estudo de Iwata et al. (1994) teve por objetivo principal 
identificar as variáveis que estariam associadas e que serviriam para manter a ocorrência do comportamento autolesivo de nove crianças com atraso do desenvolvimento, por meio de observações repetidas em diferentes ambientes análogos. Com o intuito de que se aproximassem de contingências de reforçamento para o comportamento autolesivo, três condições experimentais foram planejadas: "atenção social", que simulava uma contingência de reforçamento positivo por atenção do adulto; "demanda", que simulava uma contingência de reforçamento negativo por fuga de tarefas; e "sozinho", que simulava uma contingência de reforçamento automático. Além disso, foi planejada uma condição controle, "brincadeira livre", que simulava uma contingência de reforçamento diferencial de outros comportamentos.

Na condição de "atenção social", o experimentador instruía a criança a brincar com os brinquedos disponíveis na sala. Em seguida, sentava-se afastado da criança, aparentando ler um livro ou revista. $\mathrm{O}$ experimentador dava atenção à criança a cada episódio de autolesão, na forma de frases de preocupação e/ou repreensão pareadas a um breve contato físico de natureza não punitiva. Todos os outros comportamentos emitidos pela criança eram ignorados.

$\mathrm{Na}$ condição de "demanda", atividades apropriadas para cada criança eram selecionadas, seguindo os critérios de serem tarefas que não se completavam espontaneamente e de serem de difícil execução. Sentado a uma mesa junto com a criança, o experimentador dava uma instrução verbal para a realização da tarefa e esperava cinco segundos para que ela começasse a responder. Após esse intervalo, se nenhuma resposta ocorresse, o experimentador repetia a instrução, apresentava um modelo da resposta correta e aguardava mais cinco segundos. Caso a criança não respondesse nesse período, repetia-se a instrução, além de se direcionar fisicamente a criança para completar a tarefa. Reforçava-se com elogio sempre que a criança completava a resposta, iniciando-se a próxima tentativa. O experimentador consequenciava respostas de autolesão terminando imediatamente a tentativa (retirava os materiais) e virando-se de costas para a criança por 30 segundos, com 30 segundos adicionais para a repetição da autolesão.

Na condição "sozinho", a criança era colocada na sala de terapia na ausência do experimentador, sem acesso a quaisquer brinquedos ou materiais que pudessem servir como fontes de estimulação externa.

Na condição de "brincadeira livre", vários brinquedos estavam disponíveis e o experimentador aproximava-se da criança, permitindo que ela se movesse livremente, brincasse sozinha ou cooperativamente e sem qualquer tipo de demanda. A ausência de autolesão era reforçada com elogio e breve contato físico, pelo menos uma vez a cada 30 segundos. Comportamentos auto-lesivos eram ignorados, com exceção daqueles que atingiam o critério de severo risco físico para a criança, casos em que se interrompia a sessão.

Após repetidas séries de aplicação das quatro condições com cada criança participante, os resultados indicaram que a ocorrência do comportamento autolesivo variou amplamente, tanto entre diferentes participantes como entre as diferentes condições para cada participante. Para seis das nove crianças, altas taxas de comportamento autolesivo estiveram associadas com uma condição específica, o que sugere que a autolesão pode ser produto de diferentes contingências de reforçamento. Por ser realizado em ambientes análogos às situações naturais, os autores concluíram que o método utilizado apresentou como vantagens a melhor identificação e controle dos eventos relacionados ao comportamento, além de apresentar uma duração reduzida, contrapondo-se a outros estudos que mencionavam a necessidade de um longo período para a realização de uma análise funcional do comportamento.

Utilizando-se da proposta de Iwata et al. (1994), um outro estudo foi realizado por Iwata et al. (2000), com o objetivo de avaliar os efeitos de um programa de treinamento a onze estudantes de Psicologia para o estabelecimento de competência para aplicar esse método de análise funcional.

No estudo de Iwata et al. (2000), os participantes deveriam conduzir sessões simuladas como terapeutas nas condições de "atenção", "demanda" e "brincadeira livre", sendo que estudantes de pós-graduação em Análise do Comportamento desempenhavam o papel de clientes. Os resultados mostraram altos desempenhos em linha de base, com média de 69,9\% de acertos. Após o treino ${ }^{1}$, todos os desempenhos melhoraram, com média de acertos de 97,5\%. O desempenho dos participantes desde a linha de base, com quase $70 \%$ de acertos, contrariou a suposição de investigações anteriores a respeito da necessidade de treinamento exaustivo para a aquisição das habilidades para conduzir a análise funcional do comportamento. Tal argumento ficou ainda mais evidente com a constatação de uma média acima dos $95 \%$ de precisão depois de um treino de cerca de duas horas.

Com o intuito de investigar diretamente o treinamento de professores, Moore et al. (2002) conduziram um experimento tendo como referência o estudo de Iwata et al. (2000). Considerando que neste último não foram obtidas medidas do desempenho dos participantes na condução do procedimento em settings aplicados, Moore et al. (2002) pretenderam examinar um método de treinamento de três professores do ensino fundamental (regular e especial) para a aplicação do método proposto por Iwata et al. (2000). Foram realizadas sessões de análise funcional nas condições de "atenção" e "demanda", tanto em situação simulada, na qual um estudante de pós-graduação em Análise do Comportamento fazia o papel do aluno, como no ambiente natural da sala de aula. O comportamento do aluno, que era o alvo da análise funcional, foi o de gritar, quando emitido sem a permissão do professor para falar. Os resultados mostraram que os professores atingiram alto nível de desempenho na aplicação do procedimento de análise funcional, com mais de $95 \%$ de acertos. Na situação aplicada em sala de aula, a porcentagem de acertos também foi alta, sugerindo que professores, se treinados adequadamente, podem aprender a implementar métodos de análise funcional com alto nível de integridade.

Tendo em vista os resultados favoráveis ao treinamento de pessoas para aplicar o método de análise funcional do comportamento que foram obtidos nos estudos de Iwata et al. (2000) e Moore et al. (2002), Wallace, Doney, Mintz-Resudeck e Tarbox (2004) conduziram uma nova investigação com o objetivo de replicá-los e estender suas conclusões.

Wallace et al. (2004) realizaram um treinamento no formato 
de workshop com dois professores e um psicólogo escolar, e as sessões simuladas de análise funcional ocorreram nas condições de "atenção", "demanda" e "brincadeira". Após o treinamento houve sondagem de generalização, com um participante conduzindo as sessões de análise funcional na sala de aula. $\mathrm{O}$ comportamento do aluno, que era o alvo da análise funcional, foi o de bater em seu próprio corpo.

Os dados encontrados mostraram que, durante a simulação em linha de base, nenhum participante obteve mais de 50\% de acertos. Depois das três horas de treinamento no workshop, houve melhora significativa no desempenho dos participantes que implementaram cada uma das condições com mais de $90 \%$ de acertos. Os resultados de Wallace et al. (2004) sugerem que os professores e o psicólogo escolar apresentaram alto nível de proficiência na implementação da análise funcional do comportamento, corroborando os achados de Iwata et al. (2000) e Moore et al. (2002).

Apesar de os autores afirmarem nos estudos citados que ensinaram pessoas a realizar uma análise funcional do comportamento, nenhum deles informou que os participantes tenham analisado e interpretado os dados sobre o comportamento da criança decorrentes do método implementado e nem que tenham selecionado uma intervenção apropriada, considerando as variáveis que evocavam e mantinham o comportamento tido como inadequado. Tais estudos ensinaram aos participantes a aplicação efetiva de um procedimento de análise funcional do comportamento, tanto no setting simulado como no natural; sem, no entanto, levá-los a olhar para o que aconteceu com a frequência do comportamento da criança quando dessa aplicação. Iwata et al. (2000) e Wallace et al. (2000) mencionam, inclusive, que treinaram apenas parte do que compreende uma análise funcional do comportamento.

Em uma linha diferente de investigação, Myers e Holland (2000) aplicaram 209 questionários a professores, com o objetivo de verificar se tais profissionais, ao proporem uma intervenção que pudesse ser implementada em sala de aula, consideravam a função de comportamentos tidos como indesejáveis dos alunos. Os questionários continham cenários escritos que apresentavam situações de sala de aula, nas quais um aluno exibia os comportamentos indesejáveis. Os comportamentos dos alunos sugeriam as funções de "fuga" (reforçamento negativo), "atrair atenção do professor" e "atrair atenção dos colegas" (ambos reforçamento positivo). Os resultados indicaram que $50 \%$ dos professores propuseram uma intervenção apropriada para a função de "atrair atenção do professor", enquanto que, para as demais funções, menos de um terço dos professores propuseram intervenções apropriadas. Os autores concluem que poucos professores consideram as contingências que mantêm os comportamentos inadequados do aluno ao escolher uma intervenção, e ressaltam a utilidade de novos estudos relacionados ao treinamento de professores para avaliar o que mantém tais comportamentos.

Tendo como ponto de partida as conclusões de Myers e Holland (2000), o objetivo do presente estudo foi ensinar professoras de Educação Infantil que apresentavam em suas salas de aula alunos com comportamentos considerados por elas inadequados, a analisar e interpretar dados gerados pela aplicação do método proposto por Iwata et al. (2000), em uma situação simulada, mostrada por meio de filmes diversos, como parte de uma análise das contingências de reforçamento que mantinham tais comportamentos.

O termo "análise das contingências de reforçamento" será utilizado no presente trabalho a partir deste ponto - de preferência ao termo "análise funcional do comportamento", utilizado nos estudos mencionados - em razão de estar comprometido com o sistema conceitual da Análise do Comportamento, diferentemente do termo "análise funcional" (para discussão a respeito, ver Andery, Micheletto, \& Sério, 2001).

Os objetivos específicos deste estudo foram: ensinar professoras a observar e registrar dados sobre comportamentos de alunos mostrados durante a exibição de filmes; e ensinar os repertórios de análise e interpretação dos dados registrados. Para tanto, analisar foi definido como identificar o que acontece com a frequência do comportamento do aluno em decorrência do procedimento utilizado nas diferentes situações de aplicação simuladas; e interpretar, como estabelecer relações ordenadas entre o evento antecedente, a resposta e a consequência, concluindo sobre o que provavelmente mantém determinado comportamento em certa situação.

\section{Método}

\section{Participantes}

Participaram do estudo três professoras de uma escola de Educação Infantil do interior do estado de São Paulo. Todas apresentavam ao menos um aluno que exibia comportamentos considerados por elas inadequados. As participantes foram selecionadas entre as sete professoras da escola onde se realizou a coleta de dados, conforme a disponibilidade dos horários livres durante o turno de trabalho. Seguindo este critério, os horários livres de uma participante não deveriam coincidir com os de outra participante, para evitar perdas de sessões. Os horários livres correspondiam ao período em que os seus alunos estavam em aulas com outros professores. A coleta foi realizada em uma sala de aula da escola onde as professoras trabalhavam.

\section{Material}

Foram utilizados: termo de consentimento livre e esclarecido; apresentação em PowerPoint com alguns conceitos da Análise do Comportamento; avaliação escrita sobre os conceitos da Análise do Comportamento constantes da apresentação; 14 filmes em DVD; folha de registro de observação dos filmes e gabarito da folha de registro.

Os filmes tinham nove minutos de duração cada e foram produzidos especialmente para o presente estudo. Todos os filmes exibiam diferentes situações de interação entre uma professora e um aluno (ou aluna), sendo que sete filmes mostravam um comportamento tido como inadequado do aluno (chamado de comportamento-alvo), mantido pela atenção social da professora (contingência de reforçamento positivo); os outros sete mostravam o comportamento-alvo mantido pela fuga de tarefas escolares (contingência de reforçamento negativo).

Os filmes mostravam uma professora realizando a 
aplicação do método proposto por Iwata et al. (2000), em uma situação simulada, para avaliar um comportamento considerado inadequado de um aluno. Em cada filme, uma atriz desempenhava o papel da professora e outra desempenhava o papel do aluno.

Cada um dos filmes foi composto por três cenas, de três minutos cada, que correspondiam às condições de "atenção" (contingência de reforçamento positivo por atenção social do professor), "fuga de demandas" (contingência de reforçamento negativo por fuga de tarefas pedagógicas) e "brincadeira" (contingência de reforçamento diferencial de outros comportamentos), como propostas por Iwata et al. (2000).

Os filmes foram compostos por cinco classes de respostas do aluno: 1) comportamento-alvo; 2) outros comportamentos disruptivos; 3) brincar apropriado; 4) obedecer às instruções da professora; 5) iniciar interação social apropriada.

Para os filmes que mostravam comportamento-alvo mantido pela atenção social da professora, havia de cinco a sete ocorrências desse comportamento nas cenas de "atenção", de uma a duas ocorrências nas cenas de "fuga de demandas" e uma ou nenhuma ocorrência nas cenas de "brincadeira". Para os filmes que mostravam comportamento-alvo mantido pela fuga de tarefas, havia de cinco a sete ocorrências desse comportamento nas cenas de "fuga de demandas", de uma a duas ocorrências nas cenas de "atenção" e uma ou nenhuma ocorrência nas cenas de "brincadeira".

O material foi organizado em sete conjuntos com dois filmes cada. Em cada conjunto, um filme mostrava o comportamentoalvo mantido por uma contingência de reforçamento positivo e o outro, o comportamento-alvo mantido por uma contingência de reforçamento negativo. Foi descrito um comportamentoalvo diferente para cada conjunto, sendo eles: 1) fazer manha; 2) gritar; 3) fazer má-criação; 4) levantar-se ou sentar-se em posição inadequada; 5) reclamar de doença; 6) colocar coisas na boca; 7) fazer birra.

Para cada resposta emitida pelo aluno, havia tipicamente duas respostas da professora: uma anterior à emissão da resposta pelo aluno, que se referia à situação antecedente, e uma posterior, que se referia à consequência. As classes de respostas da professora foram definidas com base nas descrições de como conduzir as sessões, propostas por Iwata et al. (2000).

A folha de registro para a observação dos filmes correspondia a um material impresso entregue para leitura e/ou como exercício a ser completado por escrito pelas participantes. Esta continha uma definição topográfica de um comportamento-alvo a ser observado, seguida por um quadro com quatro colunas: intervalo em minutos; "situação antecedente"; "resposta" (do aluno); e "consequência". Linhas tracejadas horizontais delimitavam o espaço para cada uma das três cenas dos filmes ("atenção", "fuga de demandas" e "brincadeira"). Cada um dos três espaços foi subdividido por linhas horizontais não segmentadas em seis intervalos de 30 segundos, com início em 00:00 a 00:30 segundos e término em 02:30 a 03:00 minutos.

O gabarito da folha de registro referia-se a um material impresso com uma folha de registro modelo para cada um dos filmes, preenchida pela pesquisadora.

\section{Procedimento}

Após a assinatura do termo de consentimento livre e esclarecido, foi realizada pela pesquisadora uma entrevista inicial com cada participante, com o intuito de que descrevessem os comportamentos dos alunos que elas consideravam inadequados. Em seguida, observações e filmagens em sala de aula foram realizadas durante uma semana, para verificar se os comportamentos descritos pelas professoras ocorriam com frequência e em que condições isso se dava. Com base nas entrevistas e nas observações, foram definidos e descritos topograficamente os sete diferentes comportamentos-alvo do aluno exibidos nos filmes.

A coleta ocorreu em sessões individuais de 30 minutos, duas vezes por semana (em média). Em cada sessão exibia-se um dos filmes de cada conjunto, randomizando-se a ordem de apresentação dos dois filmes do conjunto, bem como a ordem das cenas de "atenção", "fuga de demandas" e "brincadeira" em cada um dos filmes.

No procedimento padrão aplicado durante a coleta, as participantes deveriam observar o comportamento-alvo do aluno no filme exibido e, a cada 30 segundos, a cena em exibição era pausada, para que elas lessem os registros na folha ou registrassem a ocorrência ou não ocorrência da resposta, bem como a dos eventos antecedentes e consequentes nos intervalos em que o comportamento-alvo tinha ocorrido. Não era informada às participantes qual a condição ("atenção", "fuga de demandas" ou "brincadeira") da cena que estava sendo exibida.

Terminada a exibição de cada filme, as participantes, dependendo do passo em que estivessem, liam as respostas fornecidas ou respondiam as seguintes questões sobre os registros feitos, referentes à análise e à interpretação dos dados observados e registrados: 1a) Quantas vezes o comportamentoalvo ocorreu em cada cena?; 1b) Compare o que aconteceu com a frequência do comportamento-alvo nas três cenas: em qual cena a frequência do comportamento-alvo foi maior?; 2) Na cena em que o comportamento-alvo ocorreu com maior frequência, qual a situação antecedente típica, isto é, que ocorre mais vezes?; 3) Na cena em que o comportamento-alvo ocorreu com maior frequência, qual é tipicamente a sua consequência, isto é, a consequência que mais frequentemente ocorre?; 4) O que é possível concluir sobre o que mantém o comportamento-alvo do aluno ocorrendo?

O procedimento ocorreu em três fases: Pré-teste, Ensino (subdividido em seis passos) e Pós-teste. Na Fase de Ensino, antes do início dos passos, foi apresentada às participantes uma aula introdutória sobre os conceitos de Análise do Comportamento que estariam envolvidos no restante do procedimento, e uma avaliação para as participantes responderem por escrito sobre os conceitos ensinados. Os dados ilustrados na Tabela 1 mostram um resumo de como o estudo se desenvolveu em cada uma das fases e passos, considerando as diferenças que tinham entre as informações fornecidas ou não aos participantes.

O procedimento empregado no Pré-teste foi idêntico ao do Pós-teste. O mesmo conjunto de dois filmes foi apresentado nas duas fases e, ao assistir cada um dos filmes, as participantes deveriam realizar todos os registros a cada intervalo de 30 
Tabela 1

Itens fornecidos pela pesquisadora e itens preenchidos pelas participantes, na folha de registro e na folha de questões, em cada fase do estudo

\begin{tabular}{|c|c|c|c|c|c|c|c|c|c|}
\hline \multirow{3}{*}{ Itens } & & \multicolumn{8}{|c|}{ FASES } \\
\hline & & \multirow[t]{2}{*}{ Pré-teste } & \multicolumn{6}{|c|}{ Ensino: passos da remoção de informações } & \multirow{2}{*}{$\begin{array}{l}\text { Pós- } \\
\text { teste }\end{array}$} \\
\hline & & & 1 & 2 & 3 & 4 & 5 & 6 & \\
\hline \multirow{3}{*}{$\begin{array}{l}\text { Folha de } \\
\text { registro }\end{array}$} & $\mathrm{R}$ & is & $\star$ & $\star$ & $\star$ & $\star$ & 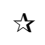 & is & औt \\
\hline & Ant & th & $\star$ & $\star$ & $\star$ & $\dot{\lambda}$ & $\dot{\lambda}$ & ts & से \\
\hline & Consq & $\dot{s}$ & $\star$ & $\star$ & $\vec{s}$ & $\vec{s}$ & is & is & 办 \\
\hline \multirow{5}{*}{$\begin{array}{l}\text { Folha de } \\
\text { questões }\end{array}$} & $1^{\mathrm{a}}$ & -- & $\star$ & $\star$ & $\star$ & $\star$ & is & -- & -- \\
\hline & $1 b$ & -- & $\star$ & $\star$ & $\star$ & $\star$ & $\dot{s}$ & -- & -- \\
\hline & 2 & -- & $\star$ & $\star$ & $\star$ & it & it & -- & -- \\
\hline & 3 & -- & $\star$ & $\star$ & $\vec{k}$ & th & $\vec{\Delta}$ & -- & -- \\
\hline & 4 & th & $\star$ & is & $\dot{\Delta}$ & is & it & is & से \\
\hline
\end{tabular}

Nota: Foram omitidos na tabela dois momentos da fase "ensino" que ocorreram antes dos passos da remoção de informações, sendo eles a aula sobre os conceitos básicos da Análise do Comportamento e a aplicação da avaliação sobre os conceitos.

$\star=$ item preenchido pela pesquisadora

is $=$ item preenchido pelas participantes

-- = item que não constou na fase

segundos, uma vez que a folha de registro estava em branco. Feitos os registros, solicitava-se que respondessem apenas à questão 4, referente ao que mantinha o comportamento-alvo ocorrendo, relativa à interpretação dos dados sobre os registros do filme.

Nos seis passos da Fase de Ensino, foi empregado um Procedimento de Remoção Gradual de Informações: no Passo 1, foram apresentados para as participantes lerem todos os modelos de registro e de respostas às questões, sendo que a cada passo, um item desses modelos era retirado e elas deveriam respondê-lo por escrito. Deste modo, no Passo 5, as participantes fizeram todos os registros e responderam a todas as questões. Já no Passo 6, foi empregado o mesmo procedimento das fases de Pré-teste e Pós-teste, diferindo apenas no conjunto de dois filmes exibido.

Durante todo o Procedimento de Remoção Gradual de Informações, a pesquisadora consequenciou cada registro feito pelas participantes nos intervalos de 30 segundos, bem como cada uma das respostas às questões, assim que terminavam de escrever o que era solicitado no item. Em caso de acerto, a pesquisadora dava um feedback, informando à participante que ela tinha acertado. Além disso, mostrava um gabarito com o modelo correspondente ao item em questão. Em caso de erro ou de acerto parcial, a pesquisadora mostrava o gabarito, pedindo que a participante lesse em voz alta o modelo de resposta correta para aquele item. Feito isso, retirava o modelo e solicitava à participante que fizesse mais uma vez o registro ou que respondesse novamente a questão. $\mathrm{O}$ acerto, nesse caso, era confirmado apenas verbalmente pela pesquisadora.

\section{Medida da resposta e confiabilidade}

Foram analisadas as respostas das participantes dadas por escrito, nas atividades de registro e de respostas às questões, no Pré-teste, nos seis passos do Procedimento de Remoção de Informações e no Pós-teste. A medida empregada foi o número de respostas corretas. Havia uma corretora independente em pelo menos $20 \%$ das atividades, estudante de pós-graduação com experiência em Análise do Comportamento. Os desacordos durante a correção das atividades foram discutidos com uma terceira corretora, professora de pós-graduação em Análise do Comportamento, para se chegar a um consenso quanto à correção mais adequada.

As respostas foram classificadas como "corretas" (C), "parcialmente corretas" (PC) e "incorretas" (I). Atribuiu-se 1.0 ponto para as "corretas", 0.5 ponto para as "parcialmente corretas" e 0.0 ponto para as incorretas.

\section{Resultados e discussão}

As Participantes 1 e 2 passaram por todas as fases do estudo. Já a Participante 3 não completou o Procedimento de Remoção Gradual de Informações ao final do ano letivo e, por isso, são apresentados apenas os dados referentes às etapas pelas quais passou, sendo elas: Pré-teste, Passos 1, 2 e 3, e Pós-teste.

A comparação do número geral de acertos obtidos pelas participantes no Pré-teste e no Pós-teste, para o conjunto dos dois filmes, está representada na Figura 1. Foram considerados, para o cálculo de acertos, cada um dos registros de ocorrência ou não ocorrência da resposta, bem como dos antecedentes e das consequências, nos casos em que o comportamento-alvo tinha ocorrido; e ainda a resposta para a pergunta "O que é possível concluir sobre o que mantém o comportamento-alvo do aluno ocorrendo?".

Tanto no Pré-teste como no Pós-teste, em que foram exibidos os mesmos dois filmes, o número máximo de acertos possíveis era 64, sendo 36 para os registros das respostas, 13 para os registros dos antecedentes, 13 para os registros das consequências e dois para as respostas à questão 4.

Os dados da Figura 1 mostram que o desempenho de todas as participantes no Pós-teste foi superior ao seu desempenho no Pré-teste. O Procedimento de Remoção Gradual de Informações produziu o desempenho esperado para as Participantes 1 e 2 ao fazer o registro dos eventos antecedentes das respostas e das consequências, bem como ao responder a questão sobre o 


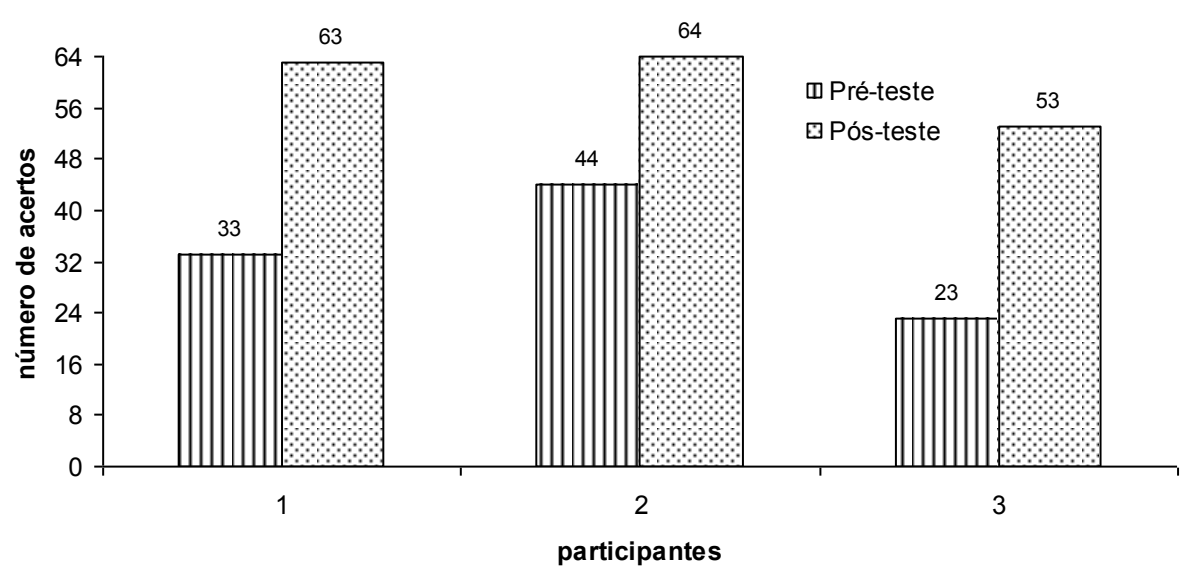

Figura 1: Número total de acertos de cada participante no Pré-teste e no Pós-teste.

que mantinha o comportamento-alvo do aluno nos dois filmes exibidos. Apesar de o número de acertos da Participante 3 ter ficado abaixo do das demais participantes, seus acertos do Pósteste superaram os do Pré-teste.

A melhora no desempenho das participantes verificada no Pós-teste pode ser comparada aos resultados encontrados por Iwata et al. (2000) e Wallace et al. (2004). No estudo de Iwata et al. (2000), o índice de acertos dos participantes na implementação do método proposto foi alto desde a linha de base, superando os $50 \%$ de acertos, mas não ultrapassando os $90 \%$ de acertos. Após o procedimento de ensino implementado, o desempenho de todos os participantes superou os $90 \%$ de acertos, sendo quase em sua totalidade acima dos $95 \%$ de acertos. No estudo de Wallace et al. (2004), no qual participaram dois professores, o desempenho dos participantes na linha de base não superou os $50 \%$ de acertos, enquanto que, depois de três horas de workshop, atingiu mais de $90 \%$ de acertos. No presente trabalho, do mesmo modo como ocorreu nos dois estudos anteriores, foi também possível ensinar as participantes a realizar parte do que compreende uma análise de contingências, com alto nível de desempenho como resultado.

Ao fazer uma comparação entre os acertos obtidos para cada um dos dois filmes separadamente, tendo como referência cada participante individualmente, verificou-se que não houve diferença no total de acertos para cada tipo de filme. O número total de acertos das Participantes 1 e 2, tanto no Pré-teste como no Pós-teste, foi muito semelhante para os dois filmes (aquele em que o comportamento-alvo do aluno era mantido pela atenção da professora e aquele em que era mantido pela fuga de tarefas). Apenas a Participante 3, no Pós-teste, apresentou um número de acertos inferior para o filme em que o comportamento era mantido pela fuga de tarefas ( 23 acertos), em relação ao número de acertos para o filme em que o comportamento era mantido pela atenção da professora (30 acertos).

A seguir, são apresentados os resultados obtidos pelas participantes em todas as fases do estudo. A Figura 2 apresenta a evolução das participantes ao registrar a ocorrência ou não ocorrência das respostas, os eventos antecedentes e as consequências a cada intervalo de 30 segundos, durante a exibição dos filmes.
Na Figura 2, verifica-se que as Participantes 1 e 2 apresentaram uma evolução similar: erros no Pré-teste, que foram praticamente eliminados durante a Fase de Ensino e no Pós-teste.

A Participante 1 apresentou três erros durante a Fase de Ensino: dois nos registros dos eventos antecedentes, nos Passos 4 e 6; e um para o registro das consequências, no Passo 4. No Pós-teste, verificou-se que acertou os registros de todos os eventos antecedentes e consequentes, mas apresentou um erro para o registro da ocorrência da resposta, do tipo falso positivo (comportamento-alvo não tinha ocorrido, mas a participante registrou sua ocorrência). Tais dados indicam uma evolução acentuada em relação ao seu desempenho no Pré-teste, em que tinha errado todos os registros dos eventos antecedentes e consequentes.

A Participante 2, que apresentou alguns erros nos registros dos antecedentes, das respostas e das consequências no Pré-teste, acertou todos os registros nos passos da remoção de informações e no Pós-teste.

A Participante 3 não apresentou uma melhora tão acentuada em seu desempenho no Pós-teste em relação ao Pré-teste, se comparada às outras participantes. Seis dos erros apresentados no Pós-teste referiam-se aos registros das consequências, para as cenas de "fuga de demandas" (cinco para o filme em que o comportamento-alvo era mantido por uma contingência de reforçamento negativo e um para o filme em que o comportamento-alvo era mantido por uma contingência de reforçamento positivo), no qual a participante escrevia sistematicamente: "A professora se afasta da criança". Em todos os casos, era imprescindível ter escrito que a professora retirava os materiais do aluno, que se livrava da tarefa, assim como ela fez no Passo 3. Tais erros no Pós-teste foram surpreendentes, uma vez que, tendo interrompido o procedimento de remoção gradual de informações no Passo 3, a participante foi ensinada apenas a registrar as consequências.

A ausência de erros nos registros da Participante 2 desde o início da Fase de Ensino e o número muito pequeno de erros da Participante 1 durante a mesma fase, somados ao bom desempenho de ambas no Pós-teste, evidenciam que o procedimento de remoção de informações foi eficaz para produzir 

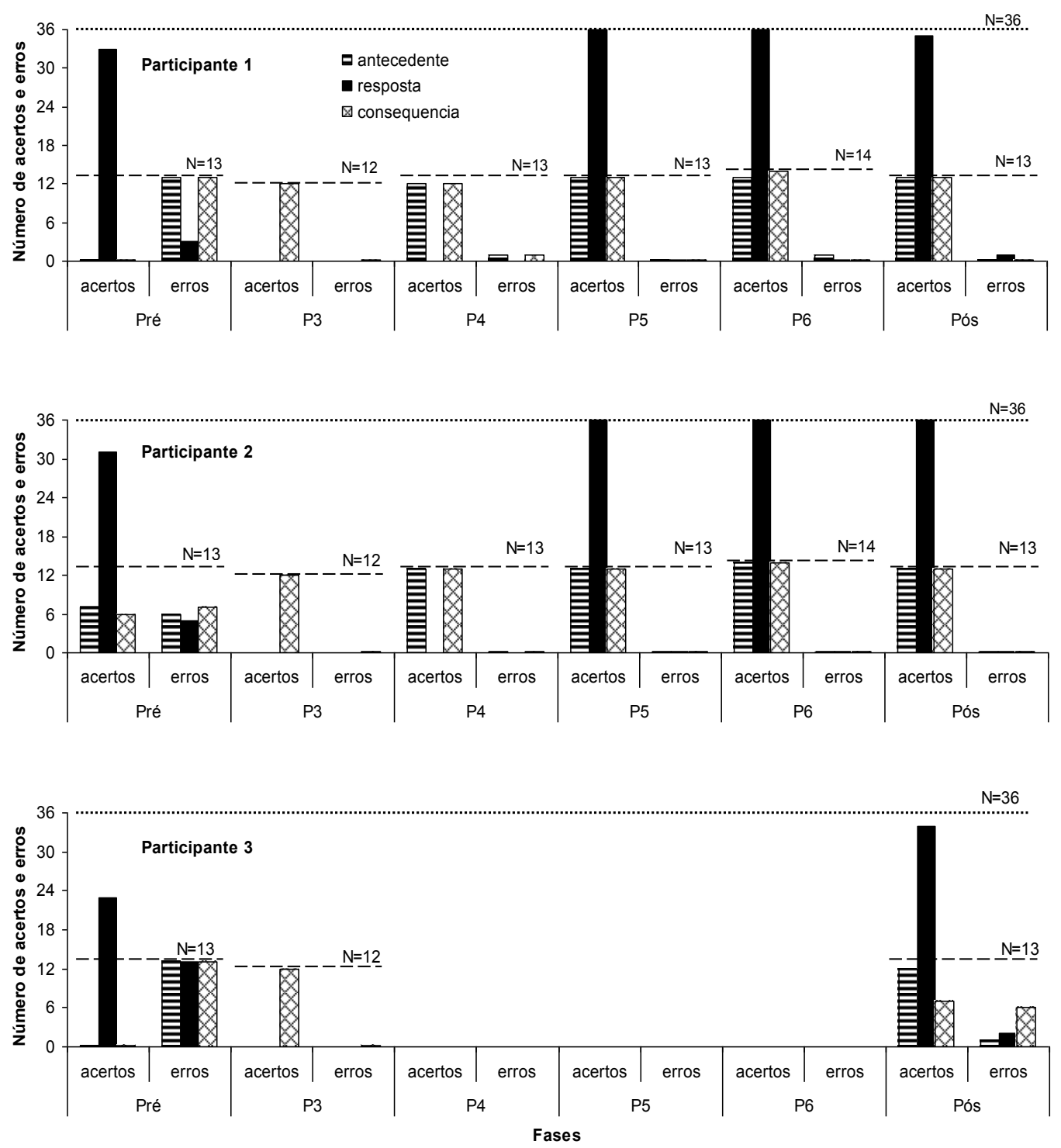

Figura 2. Número de acertos e erros das participantes 1, 2 e 3 no Pré-teste, no Pós-teste e em cada passo da Fase de Ensino, nos registros dos eventos antecedentes, das respostas e das consequências durante a exibição dos filmes.

Nota. As linhas horizontais indicam o número máximo de acertos possíveis em cada item dos registros, sendo que a linha superior (pontilhada) representa o máximo de acertos nos registros das respostas e a linha inferior (segmentada), nos registros dos antecedentes e das consequências.

Os Passos 1 e 2 foram omitidos para todas as participantes porque não exigiam os registros como parte de suas tarefas; os Passos 4, 5 e 6 estão em branco para a Participante 3, pois ela não passou por essas etapas.

os repertórios de observação e de registro dos eventos típicos das contingências de três termos representadas em cada filme e que os modelos de registro fornecidos nos passos iniciais da Fase de Ensino foram suficientes para gerar o desempenho esperado das participantes.

$\mathrm{O}$ grande número de acertos nos registros das respostas e dos eventos antecedentes da Participante 3 no Pós-teste também sugere que os modelos de registro fornecidos nos passos iniciais do da fase de ensino foram suficientes para gerar um alto nível de desempenho, como ocorreu com as Participantes 1 e 2.

Os dados da Figura 3 demonstram que, no Pré-teste, as Participantes 1, 2 e 3 responderam incorretamente a questão
4) para os dois filmes. No Pós-teste, as Participantes 1 e 2 acertaram as duas questões, enquanto a Participante 3 acertou somente a questão relativa ao filme em que o que mantinha o comportamento-alvo ocorrendo era a fuga de tarefas acadêmicas.

Os resultados do Pré-teste diferem daqueles obtidos por Myers e Holland (2000), em que metade dos participantes reconheceu a função do comportamento do aluno quando este era mantido pela atenção da professora e $30 \%$ a reconheceu quando o comportamento era mantido pela fuga de tarefas acadêmicas, sem a aplicação de qualquer estratégia de ensino. No Pré-teste do presente estudo - portanto, antes da Fase de Ensino -, nenhuma participante identificou qualquer das duas funções 

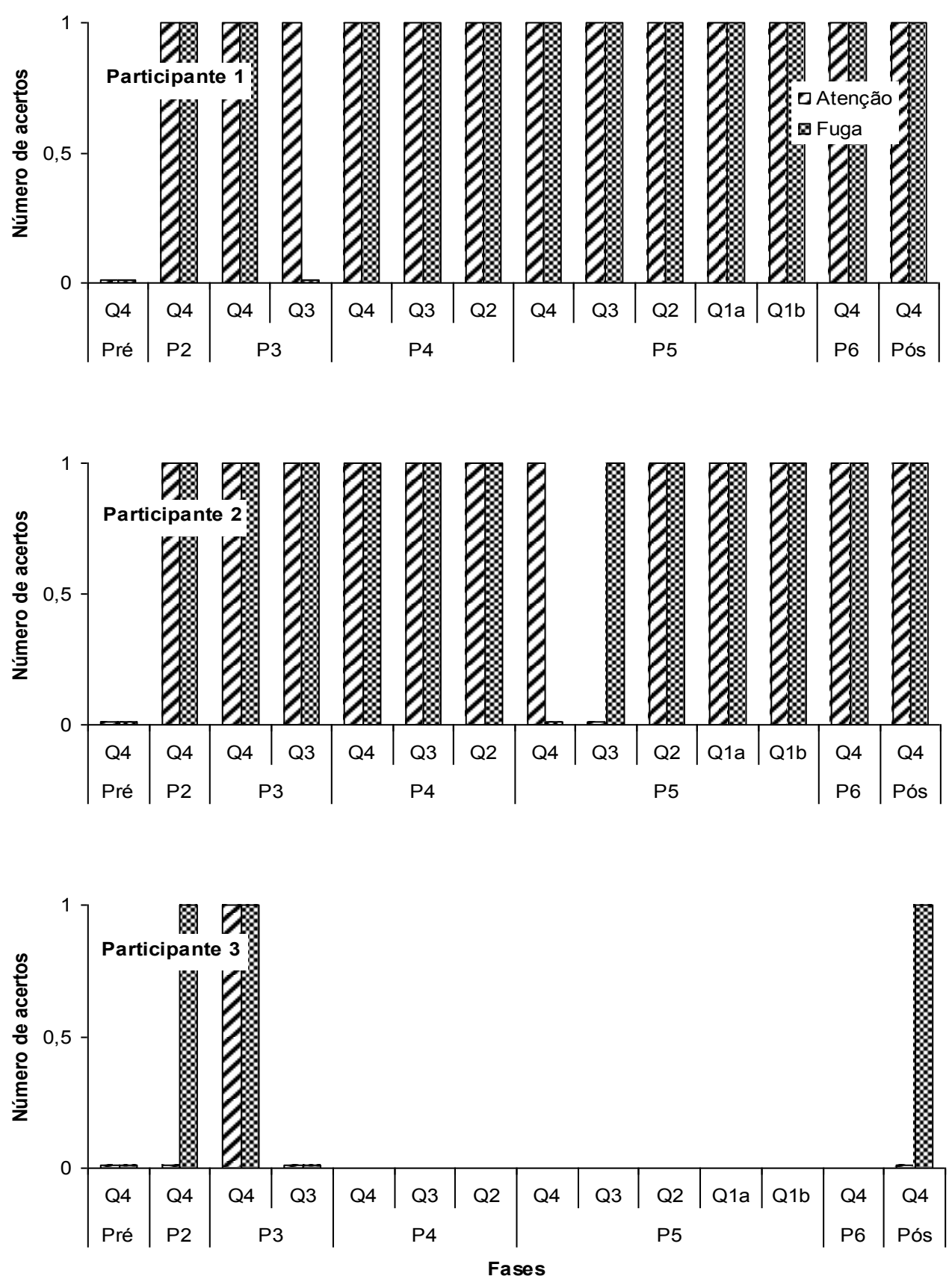

Figura 3. Número de acertos das participantes 1,2 e 3 nas questões respondidas em cada etapa do procedimento nos filmes em que o comportamento era mantido pela atenção da professora ou pela fuga de tarefas acadêmicas.

Nota. Os Passos 4, 5 e 6 estão em branco para a Participante 3, porque ela não passou por essas etapas. O Passo 1 foi omitido para todas as participantes porque não exigia as respostas às questões como parte de suas tarefas.

do comportamento do aluno (reforçamento positivo por atenção da professora ou reforçamento negativo por fuga de tarefas).

Na Figura 3, pode-se observar também que, durante o processo de remoção de informações, foram cometidos poucos erros pelas participantes ao responder as questões.

A Participante 1 apresentou maior regularidade, acertando praticamente todas as questões desde o início da remoção de informações para os dois tipos de filmes. A exceção foi um erro na resposta à questão 3 do Passo 3 para o filme em que o comportamento-alvo era mantido pela fuga de tarefas. Após a leitura do modelo de resposta correta, a Participante 1 fez a correção apropriada e, em seguida, acertou a questão relativa à interpretação dos dados.

A Participante 2 acertou quase todas as questões a partir do Passo 2 da remoção de informações. Seus dois erros ocorreram no Passo 5, sendo um na questão 4, para o filme em que o 
comportamento-alvo era mantido por reforçamento negativo; e outro na questão 3, para o filme em que o comportamento-alvo era mantido por reforçamento positivo.

A Participante 3 foi a que apresentou as maiores inconsistências ao responder as questões nos passos pelos quais passou do procedimento de remoção de informações. Um único erro ocorreu para um filme que mostrava o comportamentoalvo mantido por uma contingência de reforçamento negativo, na questão 3 do Passo 3. Mais erros da Participante 3 foram verificados para os filmes que mostravam o comportamentoalvo mantido por uma contingência de reforçamento positivo: na questão 4 do Passo 2; na questão 3 do Passo 2; e na questão 4 do Pós-teste.

A Fase de Ensino como um todo se mostrou eficaz e sua duração não ultrapassou 8 horas. Para a Participante 1 , foram realizadas 21 sessões, e o tempo gasto foi de aproximadamente 8 horas; para a Participante 2, foram realizadas 17 sessões, e o tempo gasto aproximado foi de 6 horas e 15 minutos; e para a Participante 3, foram realizadas 12 sessões, e o tempo gasto aproximado foi de 3 horas e 50 minutos. Esses períodos são relativamente curtos se comparados aos períodos de formação completa e de vasta experiência em Análise do Comportamento usualmente reconhecidos como necessários para se realizar uma análise de contingências. No presente trabalho, todavia, ensinouse às participantes apenas uma parte daquilo que se entende por uma análise de contingências.

É importante considerar que a duração da Fase de Ensino do presente estudo foi similar ou um pouco maior que a dos estudos anteriores (Iwata et al., 2000; Moore et al., 2002; Wallace et al., 2004), que buscaram ensinar uma parte diferente de uma análise de contingências, correspondente à aplicação de um procedimento para testar as variáveis ambientais relacionadas à ocorrência do comportamento-alvo, em diferentes situações análogas.

\section{Conclusão}

Os resultados obtidos sugerem que as estratégias de ensino empregadas no presente estudo foram efetivas para o alcance dos objetivos. Com base nesses achados, é possível dizer que professoras podem aprender a realizar parte de uma análise de contingências em um tempo relativamente curto, quando ensinadas adequadamente.

Algumas limitações do estudo referem-se: à ausência de uma avaliação da generalização dos repertórios ensinados para o ambiente natural, por meio de filmes que mostrem situações reais de sala de aula, devidamente editados; aos filmes que, por exibirem a aplicação dos procedimentos propostos por Iwata et al. (2000), não retratavam os procedimentos usados pelas participantes em sala de aula; e à ausência de dados mais conclusivos sobre os efeitos da aula e da avaliação sobre os conceitos da Análise do Comportamento.

Conclui-se que os resultados obtidos foram favoráveis ao ensino de professores a fazer parte de uma análise de contingências. Novos estudos poderiam dar continuidade a este, mostrando à utilidade de se estender a análise de contingências a outros profissionais, sem formação ou experiência em Análise do Comportamento, a outros contextos de serviços e também a grupos de participantes.

\section{Referências}

Andery, M. A. P. A., Micheletto, N., \& Sério, T. M. A. P. (2001). Análise funcional na Análise do Comportamento. In H. J. Guilhardi, M. B. B. P. Madi, P. P. Queiroz, \& M. C. Scoz (Orgs.), Sobre Comportamento e Cognição: expondo a variabilidade (Vol. 8, pp. 148-157). Santo André: ESETec.

Carr, E. G., Langdon, N. A., \& Yarbrough, S. C. (1999). Hypothesis-based intervention for severe problem behavior. In A. C. Repp \& R. H. Horner (Orgs.), Functional Analysis of Problem Behavior: from Effective Assessment to Effective Support (pp. 9-31). Belmont: Wadsworth.

Iwata, B. A., Dorsey, M. F., Slifer, K. J., Bauman, K. E., \& Richman, G. S. (1994) Toward a functional analysis of self-injury. Journal of Applied Behavior Analysis, 27(2), 197-209.

Iwata, B. A., Wallace, M. D., Kahng, S. W., Lindberg, J. S., Roscoe, E. M., Conners J., Hanley, G. P., Thompson, R. H., \& Worsdell, A. S. (2000). Skill acquisition in the implementation of functional analysis methodology. Journal of Applied Behavior Analysis, 33(2), 181-194.

Matos, M. A. (1999). Análise funcional do comportamento. Estudos de Psicologia (Campinas), 16(3), 8-18.

Moore, J. W., Edwards, R. P., Sterling-Turner, H. E., Riley, J., DuBard, M., \& McGeorge, A. (2002). Teacher acquisition of functional analysis methodology. Journal of Applied Behavior Analysis, 35(1), 73-77.

Myers, C. L., \& Holland, K. L. (2000). Classroom behavioral interventions: do teachers consider the function of the behavior? Psychology in the Schools, $37(3), 271-280$.

Repp, A. C., \& Horner, R. H. (1999). Introduction to functional analysis. In A. C. Repp \& R. H. Horner (Orgs.), Functional analysis of problem behavior: from effective assessment to effective support (pp. 1-6). Belmont: Wadsworth.

Roscoe, E. M., Carreau, A., MacDonald, J., \& Pence, S. T. (2008). Further evaluation of leisure items in the attention condition of functional analyses. Journal of Applied Behavior Analysis, 41(3), 351-364.

Wallace, M. D., Doney, J. K., Mintz-Resudek, C. M., \& Tarbox, R. S. F. (2004) Training educators to implement functional analyses. Journal of Applied Behavior Analysis, 37(1), 89-92. 
1. Faz-se, neste ponto, a ressalva de que se optou por manter as expressões "treinamento" e "treino" ao longo desta introdução, como utilizadas originalmente pelos autores dos estudos apresentados nesta seção, embora seja possível compreender que as expressões "treinamento" e "treino" refiram-se a estratégias de ensino de técnicas de avaliação comportamental e de manejo de contingências ambientais.

Carolina Porto de Almeida, mestre em Psicologia Experimental pela Pontifícia Universidade Católica de São Paulo, é psicóloga clínica e supervisora de estágio em saúde do curso de Psicologia da Faculdade de Jaguariúna (FAJ). Endereço para correspondência: Rua Ferreira Penteado, 1338, apto 71, Cambuí, Campinas - SP. CEP: 13010-907. Telefones: (19) 3252-3409/(19) 8183-1548. E-mail: carol_dpa@yahoo.com

Maria Eliza Mazzilli Pereira, doutora Pontifícia Universidade Católica de São Paulo, é professora e coordenadora do Programa de Estudos Pós-Graduados em Psicologia Experimental: Análise do Comportamento e Professora na Pontifícia Universidade Católica de São Paulo. E-mail: memazzilli@pucsp.br 